\title{
Refugia Ditinjau Dari Konsep Gulma Pengganggu Dan Upaya Konservasi Musuh Alami
}

\author{
Asyik Nur Allifah AF ${ }^{1}$, Rosmawati $\mathbf{T}^{\mathbf{2}}$, Zamrin Jamdin ${ }^{3}$ \\ 1,2,3Program Studi Pendidikan Biologi, Fakultas Ilmu Tarbiyah dan Keguruan Institut \\ Agama Islam Negeri Ambon \\ ${ }^{1}$ E-mail: asyik.nur.allifah.af@gmail.com \\ ${ }^{2}$ Email: rosmawatit@gmail.com \\ ${ }^{3}$ Email: zamrinj@yahoo.com
}

\begin{abstract}
Abstrak: Gulma merupakan bagian dari OPT (Organisme Pengganggu Tanaman) selain hama dan penyakit tanaman. Gulma menimbulkan kerusakan secara perlahan, dikarenakan kompetisi dengan tanaman budidaya untuk memperoleh hara, air, cahaya, $\mathrm{CO}^{2}$ dan ruang tumbuh. Gulma bersifat merugikan dan mengganggu sehingga manusia berusaha untuk mengendalikannya. Dari berbagai aspek kehidupan baik kesehatan, estetika, lingkungan hidup dan bidang usaha tani, gulma dapat menggangu habitat alami dan keindahan. Gulma selalu dianggap sebagai tumbuhan eksotik atau pendatang yang bersifat invasif dan berpotensi mengganggu lingkungan setempat. Namun demikian tidak semua gulma berperan negatif dan berpotensi mengganggu. Gulma juga mampu memberikan habitat yang nyaman bagi berkembangnya musuh alami dalam agrosekosistem. Refugia merupakan area tanaman gulma yang dapat menyediakan tempat perlindungan, sumber pakan atau sumberdaya yang lain bagi musuh alami seperti predator dan parasitoid. Upaya konservasi musuh alami menggunakan refugia merupakan salah satu alternatif pengendali organisme pengganggu tanaman seperti hama.
\end{abstract}

\section{Kata Kunci: Refugia, Gulma, Konservasi, Musuh Alami}

\begin{abstract}
Weed is a part of OPT (Plant Disturbing Organism) besides plant pests and diseases. Weeds cause damage slowly, due to competition with cultivated plants to obtain nutrients, water, light, $\mathrm{CO} 2$ and growing space. Weeds are harmful and disturbing so humans try to control them. From various aspects of life both health, aesthetics, environment and the field of farming, weeds can interfere with natural habitat and beauty. Weeds are always considered as exotic plants or migrants that are invasive and potentially disrupt the local environment. However, not all weeds play a negative and potentially disturbing role. Weeds are also able to provide a comfortable habitat for the development of natural enemies in the agrosecosystem. Refugia is a weed plant area that can provide shelter, food sources or other resources for natural enemies such as predators and parasitoid. Efforts to conserve natural enemies using refugia are one alternative to controlling plant pest organisms such as pests.
\end{abstract}

Keywords: Refugia, Weeds, Conservation, Natural Enemies

BIOLOGI SEL (VOL 8 NO 1 EDISI JAN-JUN 2019 ISSN 2252-858X/E-ISSN 2541-1225) PAGE 82 
Gulma merupakan tumbuhan yang kehadirannya tidak dikehendaki oleh manusia. Keberadaan gulma menyebabkan terjadinya persaingan antara tanaman utama dengan gulma. Gulma yang tumbuh menyertai tanaman budidaya dapat menurunkan hasil baik kualitas maupun kuantitasnya (Widaryanto, 2010). Gulma mempunyai kemampuan bersaing yang kuat dalam memperebutkan $\mathrm{CO} 2$, air, cahaya matahari dan nutrisi. Pertumbuhan gulma dapat memperlambat pertumbuhan tanaman (Singh, 2005). Beberapa penelitian terkait gulma adalah Brown dan Brooks (2002) yang menyatakan bahwa gulma menyerap hara dan air lebih cepat dibanding tanaman pokok. Gulma berpengaruh langsung pada pertumbuhan dan hasil tanaman kedelai. Persaingan antara gulma dan tanaman dalam mengambil unsur hara dan air dalam tanah dan penerimaan cahaya matahari untuk proses fotosintesis, menimbulkan kerugian dalam produksi baik kualitas maupun kuantitas.

Gulma dalam ekosistem pertanian terbagi atas penggangu dan non pengganggu. Refugia merupakan area tumbuhan gulma yang tidak mengganggu karena perannya sebagai mikrohabitat yang menyediakan tempat berlindung secara spasial dan/atau temporal bagi musuh alami hama, seperti predator dan parasitoid, serta mendukung komponen interaksi biotik pada ekosistem, seperti polinator atau serangga penyerbuk (Keppel et al., 2012). Tanaman refugia mempunyai potensi menyokong mekanisme sistem yang meliputi perbaikan ketersediaan makanan alternatif seperti nektar, serbuk sari, dan embun madu; menyediakan tempat berlindung atau iklim mikro yang digunakan serangga predator untuk bertahan melalui pergantian musim atau berlindung dari faktorfaktor ekstremitas lingkungan atau pestisida; dan menyediakan habitat untuk inang atau mangsa alternatif (Landis et al.,2000).

Sistem pertanian yang mengembangkan teknik pengendalian hama yang berbasis lingkungan, refugia diharapkan dapat menjaga kelestarian agroekosistem di lapangan, dengan merunut pada prinsip Pengendalian Hama Terpadu (PHT). PHT menitikberatkan pemanfaatan berbagai teknik pengendalian yang dikombinasikan dalam satu kesatuan program, sehingga dicapai keuntungan ekonomi yang maksimal dan memberikan dampak yang aman bagi lingkungan hidup. Secara prinsip, berbagai cara pengendalian diterapkan harus secara teknis efektif dan dapat diterapkan secara ekonomi menguntungkan, secara ekologi aman dan secara sosial budaya dapat diterima (Prabaningrum, 2015).

Aplikasi pestisida merupakan cara pengendalian hama yang banyak dilakukan oleh petani. Hal ini dilakukan dengan tujuan untuk memaksimalkan produksi padi. Secara intensif aplikasi pestisida dapat mendukung produktivitas padi sawah, namun disisi lain dapat merusak keseimbangan alami ekosistem di lahan pertanian. Terganggunya rantai makanan alami dapat meningkatkan populasi hama akibat resistensi dan berkurangnya populasi musuh alami yang mampu mengendalikan populasi hama (Muhibah dan Leksono, 2015 dalam Apriliyanto dan Sarno, 2018)). 
Kurangnya pemahaman dan pengetahuan masyarakat akan bahaya yang ditimbulkan akibat penggunaan bahan kimia, mendorong peneliti di bidang pertanian untuk mengembangkan teknik pengendalian hama yang berbasis lingkungan, dan di harapkan tetap menjaga kelestarian agroekosistem di lapangan dengan merunut kepada prinsip Pengendalian Hama Terpadu (HPT).

\section{HASIL DAN PEMBAHASAN}

\section{Tanaman Refugia}

Tanaman Refugia adalah pertanaman beberapa jenis tanaman yang dapat menyediakan tempat perlindungan, sumber pakan atau sumberdaya yang lain bagi musuh alami seperti predator dan parasitoid (Nentwig, 1998; Wratten et al., 2004). Umumnya tanaman refugia ditanam di pinggir guludan atau diluar pertanaman secara memanjang dan berbunga mencolok. Serangga-serangga musuh alami seperti kumbang, lebah, semut, dan serangga hama seperti thrips, kupu-kupu sangat tertarik dengan tanaman yang berbunga dengan warna mencolok serta berbau. Refugia adalah mikrohabitat yang menyediakan tempat berlindung secara spasial dan/atau temporal bagi musuh alami hama, seperti predator dan parasitoid, serta mendukung komponen interaksi biotik pada ekosistem, seperti polinator atau serangga penyerbuk (Keppel et al., 2012).

Pemanfaatan tanaman refugia sebagai mikrohabitat serangga hama dan musuh alami dapat diterapkan di lahan persawahan maupun lahan sayuran untuk mengendalikan hama secara alamiah. Penanaman refugia akan mengurangi biaya usaha tani untuk pengendalian hama sehingga lingkungan terjaga secara berimbang. Refugia berfungsi sebagai mikrohabitat yang diharapkan mampu memberikan kontribusi dalam usaha konservasi musuh alami. Pudjiastuti et al (2015) menyatakan bahwa suatu konsep pemecahan masalah yang dapat diterapkan dalam pengendalian hama adalah dengan cara menanam tanaman yang digunakan sebagai refugia sehingga konservasi predator dapat terus terjaga. Syarat-syarat penanaman refugia menurut Sinar Tani (2016) diantaranya adalah

a. Pilih tanaman yang memiliki bunga dan warna yang mencolok,

b. Regenerasi tanaman cepat dan berkelanjutan,

c. Benih atau Bibit mudah diperoleh,

d. Mudah ditanam

e. Dapat ditumpang sarikan dengan tanaman pematang lain.

Selanjutnya Pujiastuti et al. (2015) menyatakan bahwa serangga musuh alami seringkali memerlukan tempat berlindung sementara sebelum menemukan inang atau mangsanya.Penanaman tanaman di pinggir lahan dapat dilakukan untuk memenuhi hal tersebut. Selain bertujuan untuk mendapatkan hasil produksi sampingan, penanaman tanaman di pinggir lahan dapat berfungsi sebagai sumber makanan bagi imago baik parasitoid maupun predator dan tempat berlindung sementara. 
Refugia merupakan tumbuhan liar baik tanaman maupun gulma yang tumbuh di sekitar tanaman yang dibudidayakan, dan berpotensi sebagai mikrohabitat bagi musuh alami (baik predator maupun parasitoid). Hal ini dilakukan agar pelestarian musuh alami tercipta dengan baik. Bagi musuh alami, tanaman refugia ini memiliki banyak manfaat diantaranya adalah sebagai sumber nektar bagi musuh alami sebelum adanya populasi hama di pertanaman. Istilah gulma selalu dianggap tanaman pengganggu. Namun demikian jika populasinya masih dalam batas normal dan bisa dikendalikan, hal ini tidak akan berpengaruh pada tanaman budidaya. Refugia yang tergolong gulma terdiri dari berbagai jenis baik berbunga maupun baunya yang khas. Menurut Wahyuni et al.(2013), tumbuhan berbunga yang dijadikan tanaman refugia diharapkan dapat menjadi tempat perlindungan serta sebagai penyedia pakan bagi predator dari hama tanaman padi.

Makanan yang didapatkan predator dari tumbuhan berbunga adalah madu dan nektar dari bunga serta serangga hama yang bersembunyi pada tumbuhan tersebut. Menurut Norris (2005) dalam Wahyuni et. al (2013), selain dapat memperoleh madu dan nektar dari tumbuhan berbunga yang didatanginya, predator juga dapat menemukan mangsa yang bersembunyi di tumbuhan berbunga tersebut. Sehingga predator dapat dengan mudah memangsa mangsanya. Menurut Altieri \& Nichols (2004) dalam Kurniawati \&Edhi (2015), manipulasi habitat dapat dilakukan dengan menanam tumbuhan berbunga (insectary plant) yang berfungsi sebagai sumber pakan, inang/mangsaalternatif, dan refugia bagi musuh alami. Tumbuhanatau gulma berbunga yang berperan penting dalam konservasi musuh alami ini umumnya berasal dari famili Umbelliferae, Leguminosae, dan Compositae.

Menurut Wahyuni et.al (2013), tumbuhan berbunga yang secara alami berada pada pertanaman padi lahan konvensional di Kecamatan Ceper, Kabupaten Klaten, yaitu Alternanthera philoxeroides, Alternanthera sessilis, Eclipta prostrate (orang aring). Sedangkan tumbuhan berbunga Ruellia malacosperma, Cosmos caudatus(kenikir), Wedelia trilobata, Impatiens balsamina(pacar air), Euphorbia milii dan Arachis hypogaea(kacang tanah), merupakan tumbuhan berbunga yang ditanam oleh petani di pertanaman padi organik. Tumbuhan berbunga yang paling beragam didatangi predator pada fase vegetatif di lahan organik yaitu Alteranthera sessilis. Serangga predator yang mendatangi tumbuhan berbunga ini berasal dari famili Pentatomidae, Gryllidae, Oxyopidae dan Formicidae.SedangkanAlternanthera philoxeroides pada fase vegetatif memiliki tingkat keragaman predator tertinggi di lahan konvensional. Predator yang mendatangi tumbuhan ini yaitu berasal dari famili Coccinelidae, Dolichopodidae, Reduviidae dan Oxyopidae.

Sejauh ini refugia yang tergolong tanaman pengganggu dapat dijadikan refugia terutama yang berasal dari famili Asteraceae seperti babadotan (Ageratum conyzoides), Ajeran (Bidens pilosa L.), Bunga tahi ayam (Tagetes erecta) sangat berpotensi sebagai mikrohabitat musuh alami di lahan. Widiastuti (2000) melaporkan bahwa serangga famili 
Coccinellidae lebih menyukai tumbuhan liar dari famili Asteraceae yakni Eupatorium odoratum dan Bidens pilosa. Demikian juga tumbuhan liar yang berpotensi sebagai refugia bisa sengaja ditanam atau dibiarkan tumbuh sendiri di areal pertanaman. Tumbuhan liar yang sengaja ditanam atau tumbuh dengan sendirinya di area pertanaman antara lain, bunga legetan (Synedrella nodiflora),pegagan (Centella asiatica), rumput setaria (Setaria sp.), rumput kancing ungu (Borreria repens), dankacang hias atau kacang pentoi (Arachis pentoi) (Sinar Tani 2016).

Namun demikian ada beberapa hal yang harus diperhatikan untuk refugia yang tergolong gulma pengganggu diantaranya adalah tanaman refugia ditanam sebelum tanaman utama agar dapat dimanfaatkan sebagai tempat berlindung dan berkembang biak bagi musuh alami dan serangga pollinator yang berperan dalam polinasi yaitu perantara penyerbukan tanaman. Refugia cocok ditanam di pematang sawah. Diusahakan agar penanaman refugia sejajar dengan sinar matahari sehingga tidak menutupi atau mengganggu penyerapan sinar matahari bagi tanaman utama. Selain itu pengolahan lahan dan pemupukan yang tepat sangat dianjurkan agar tanaman refugia tumbuh sesuai yang diharapkan (Purwatiningsih st al, 2012).

\section{Refugia dan Upaya Konservasi Musuh Alami}

Refugia sangat menguntungkan serangga musuh alami dan membantu pengendalian hama dan penyakit. Penanaman refugia merupakan suatu usaha konservasi musuh alami dengan cara menanam secara bersamaan atau mendahului tanaman utama. Landis et al. (2005) menyebutkan bahwa banyak tanaman dan tumbuhan merupakan sumber pakan langsung bagi organisme musuh alami, misalnya dengan menyediakan nektar dan polen, dan secara tidak langsung menyediakan mangsa dan inang, di samping mengelola iklim mikro yang sesuai dengan kebutuhan hidup musuh alami. Selain itu, Yanuawiadi (2003) menyatakan bahwa di dalam area refugia terdapat berbagai jenis tumbuhan yang mempunyai arti penting bagi kehidupan hewan terutama Arthropoda. Keberadaan musuh alami dalam agroekosistem mempunyai peranan penting dalam pengendalian hayati organisme pengganggu tanaman (OPT).

Tindakan konservasi musush alami merupakan teknik dalam pengendalian hayati (biological control) yang sering dilakukan dan dianjurkan. Konservasi musuh alami adalah suatu upaya untuk mempertahankan keberadaan (survival) dan melestarikan musuh alami yang sudah ada di suatu tempat atau ekosistem. Konservasi umumnya dilakukan melalui manipulasi lingkungan (pengelolaan habitat) yaitu dengan mempertahankan tumbuhan inang (Susilo, 2007). Tumbuhan inang ini berfungsi sebagai ungsian (refuge) bagi hama atau inang (mangsa) suplemennya. Manipulasi habitat dapat dilakukan dengan menanam tumbuhan berbunga (insectary plant) yang berfungsi sebagai sumber pakan, inang/mangsa alternatif, dan refuji bagi musuh alami. Tumbuhan atau gulma berbunga yang berperan penting dalam konservasi musuh alami ini umumnya berasal dari famili Umbelliferae, Leguminosae, dan Compositae (Altieri \& Nichols, 
2004), dan di antaranya adalah kubis (Brassica oleraceae L), bunga matahari (Helianthus annus L), Okra (Abelmoschus esculentus L), basil (Ocimum bassilicum L), terung (Solanum melongena), dan rumput Sudan (Sorghum bicolor).

Pemilihan tumbuhan atau tanaman berbunga menurut Kurniawati dan Martono (2015) bahwa pada sistem polikultur harus memperhatikan fungsi dan peran dari tumbuhan tersebut di lingkungan, misalnya potensi untuk meningkatkan kedatangan musuh alami, meningkatkan kesuburan tanah, atau menekan populasi gulma. Harus dilakukan uji keamanan biologis terhadap tumbuhan berbunga, seperti yang dilakukan Zhon et al. (2011) terhadap bunga matahari Helianthus annuus. Selain itu, penanaman tumbuhan berbunga harus memperhitungkan struktur dan komposisinya, yang disesuaikan dengan kondisi lahan setempat dan periode berbunga dari masing-masing tumbuhan sehingga mampu menjaga populasi musuh alami tetap tinggi di sepanjang musim tanam. Masih harus selalu diperhatikan pula pemilihan jenis tumbuhan yang tepat karena selain tumbuhannya sendiri mungkin menjadi invasive, herbivora yang menyerangnya bisa juga akan berpindah ke tanaman budidaya seperti yang terjadi dengan Lantana camara di Swaziland dan Afrika Selatan (Magagula, 2011; Heshula \& Hill, 2011).

\section{KESIMPULAN}

Penelitian tentang upaya konservasi musuh alami dengan menggunakan area refugia pada agroekosistem, cukup menarik untuk dikembangkan dalam sistem pertanian karena ramah lingkungan. Konsep refugia sebagai gulma pengganggu di kalangan petani hendaknya menjadikan perhatian menyeluruh bagi pihak terkait dengan mensosialisasikan peranan dari refugia sebagai salah satu upaya konservasi musuh alami. Refugia merupakan salah satu komponen ekosistem pertanian yang diharapkan dapat mempertahankan kelengkapan komponen rantai makanan, sehingga mampu pula menciptakan kestabilan ekosistem.

\section{DAFTAR PUSTAKA}

Altieri, M. A. \& C.I. Nichols. (2004). Biodiversity and Pest Management in Agroecosystem. 2 Edition. Haworth Press Inc., New York. 236 p

Apriliyanto, E dan Sarno. (2018). Pemantauan Keanekaragaman Hama dan Musuh Alami pada Ekosistem Tepi dan Tengah Tanaman Kacang Tanah (Arachis hypogaea L.). Majalah Ilmiah Biologi Biosfera : A Scientific Journal Vol 35, No 2 Mei $2018: 69-74$

Brown, K. and K. Brooks. (2002). Bushland Weeds: a Practical Guide to their Management, Environmental Weeds Action Network (WA) Inc. Perth WA. p.102 Heshula, L.U.P., \& M.P. Hill. (2011). The Effect of Lantana camara Leaf Quality on the Performance of Falconia intermedia. BioControl 56: 925-933. 
Keppel, G., K.P. Van Niel, G.W. Wardell-Johnson, C.J. Yates, M.Byrne, L. Mucina, A.G.T. Schut, S.D. Hopper, dan S.E. Franklin. (2012). "Refugia: Identifying and understanding safe havens for biodiversity under climate change." Global Ecology and Biogeography 21 (4): 393-404. doi:10.1111/j.14668238.2011.00686.x.

Kurniawati, Nia \& Edhi Martono. (2018). Peran Tumbuhan Berbunga sebagai Media Konservasi Arthropoda Musuh Alami. Jurnal Perlindungan Tanaman Indonesia, Vol. 19, No. 2, 2015: 53-59

Landis, D.A., S.D. Wratten, dan G.M. Gurr. (2000). "Habitat Management to Conserve Natural Enemies of Arthropod Pests in Agriculture." Annu. Rev. Entomol. 45: 175-201.

Magagula, C.N. (2011). Distribution and Abundance of Ophymia camarae (Diptera: Agromyzidae) in Lantana camara (Verbenacae) in Selected Area of SwaziLand. Biocontrol Science and Technology 21:829-837.

Muhibah, T.I. \& Leksono, A.S. (2015). Ketertarikan Arthropoda terhadap Blok Refugia (Ageratum conyzoides L., Capsicum frutescens L., dan Tagetes erecta L.) dengan Aplikasi Pupuk Organik Cair dan Biopestisida di Perkebunan Apel Desa Poncokusumo. Jurnal Biotropika. 3(3): 123127.

Nentwig, W. (1998). Weedy plant spesies and their beneficial arthropod: potential for manipulation in field crops, p 49-72. In C.H. Pickett \& R.L. Bugg (eds), Enhancing Biological Control. University of Calivornia Press. Los Angeles.

Norris, R.F. \& M. Kogan. (2005). Interactions between Weeds, Arthropod Pests, and their Natural Enemies in Managed Ecosystems. Weed Science 48: 94-158.

Prabaningrum, Li. (2015). Empat Prinsip Dasar dalam Penerapan Pengendalian Hama Terpadu (PHT). (balitsa.litbang.pertanian.go.id). Diakses 18 Maret 2019

Pujiastuti Y, H.W.S. Weni, and Abu U. (2015). "Peran Tanaman Refugia terhadap Kelimpahan Serangga Herbivora pada Tanaman Padi Pasang Surut”.Prosiding Seminar Nasional Lahan Suboptimal (8-9 Oktober 2015).

Purwantiningsih B, Amin S.L, Bagyo Y. 2012. "Kajian Komposisi Serangga Polinator pada Tumbuhan Penutup Tanah di Poncokusumo Malang”. Jurnal Hayati : 17 (165-172).

Sinar Tani. (2016). "Refugia bukan sekedar penghias sawah". Sinar Tani Edisi 12-18 Oktober 2016. No. 3674. Tahun XLVII.

Singh, S. (2005). Effect of establishment methods and weed management practices on weeds and rice in ricewheat cropping system. Indian J. Weed Sci. 37 (2): 524 527.

Susilo, F.X. (2007). Pengendalian Hayati dengan Memberdayakan Musuh Alami Hama Tanaman. Graha Ilmu. Yogyakarta 
Wahyuni R, Wijayanti R, Supriyadi. (2013). "Peningkatan keragaman tumbuhan berbunga sebagai daya tarik predator hama padi". Journal of Agronomy Research2(5): 40-46.

Widaryanto, E. (2010). Teknologi Pengandalian Gulma. Fakultas Pertanian. Universitas Brawijaya. Malang.

Widiastuti. (2000). Uji Preferensi Serangga Coccinellidae pada Tanaman Famili Asteraceae. FMIPA.Universitas Brawijaya. Malang

Wratten, S, 1. Berndt, J. Tylianakis, P. Ernando \& R. Didham. (2004). Adding flora diversity to enhance parasitoid fitness and efficacy. http://www.bugwood.org/arthropod [10 November 2004].

Yanuwiadi. (2003). Pemanfaatan Serangga Berguna dalam Sistem Pertanian melalui Manipulasi Habitat. Balittas Malang. Hal 21-23

Zhon, Z, J.Y. Guo, X.W. Zheng, M. Luo, H.S. Chen \& F.W. Han. (2011). Reevaluation in the Biosecurity of Ophraella communa against Sunflower Helianthus anuus. Biocontrol Science and Technology 21: 1147-1160 